matriculated 1585, was admitted to Caius College, and died in 1663. Dr. John Hawes, F.R.C.P., came to London; he married in 1692 Margaret, the daughter of Dr. William Smith, of Chiswick, and the baptisms of his children are entered in the parish register of St. Helens, Bishopsgate, where he was churchwarden in 1701.

Among his children were William, born Aug. 30, 1704, ordained (I.incoln) 1728; and John, baptized March 12, 1706. Dr. John Hawes was buried May 24, 1736, " at the lower end of the church," his wife Dec. 11, 1741. At some time he may have lived in the parish of St. Albans, Wood Street, and later in St. Bartholomew's Close. John Hawys may be but an obscure name to writers of to-day, but these few notes suggest, I think, that he may have been a worthy and honourable physician.I am, etc.,

London. W.1.

Hugh S. Stannus.

\section{Miliary Appearances in the Lungs in Mitral Stenosis}

SIR, - I was glad to see that my article on "Miliary Appearances in the Lungs in Mitral Stenosis". (Sept. 27, p. 488) had evoked some comment, and am particularly interested to learn that Dr. Haldane G. Nelson has seen three such cases within the last twelve months or so. Two of his cases were seen shortly before death from congestive heart failure and might well have shown radiological signs representing a combination of miliary stippling and congestive shadowing. I would be most interested to see the films. The third case he describes is even more interesting, though in a clearly different category, as it was associated with a pyrexia which responded to salicylate therapy. This must almost certainly have been a case of rheumatic lung (rheumatic pneumonitis), first described, I believe, by A. E. Naish. I have seen a peculiar coarse lung mottling in this condition, but a fine stippling of the miliary type has been described by Pendergrass and Leopold (J. Amer. med. Ass., 1945, 127, 701).

I do not agree with Dr. Muriel O'Doherty's views. She describes the pathogenesis of the miliary stippling we see in the finer pneumoconioses, such as the siderosis she quotes of the West Cumberland haematite workers. Haemosiderosis is an endogenous condition. My belief is that the haemosiderinladen histiocytes are prevented from progressing along the lymph channels to the interlobular collections of lymphatic tissue. either by disturbed pressure relationships in the lymphatics due to chronic pulmonary venous congestion, or, as Prof. A. C. Lendrum suggests in a letter I have recently received from him, by the occurrence of fibrosis in the immediate neighbourhood of the choked-up alveoli. The rosette-like appearances of the individual nodules I described in the magnified photograph should, according to Dr. O'Doherty's theory, have a radio-opaque centre if these are due to hyaline degeneration in the centre of a fibrous nodule. Actually the reverse is the case, as the centre consists of a cross-section of a terminal respiratory bronchiolus, which is, of course, translucent. The finding of abundant haemosiderin-laden cells in the sputum also strongly supports the intra-acinar theory. Like Dr. O'Doherty, I would not expect an $x$-ray photograph taken to-day to be materially different from the one seen in 1946, but my reasons for doing so would be different from hers.-I am, etc.,

Sheffield.

T. E. Gumpert.

\section{Treatment of Varicose Veins}

SiR,-We surgeons rise like goldfish at feeding time to an article on varicose veins, but dislike clinics consisting mainly of them. I read with great interest the stimulating contribution of Prof. A. M. Boyd and Mr. D. J. Robertson (Sept. 20, p. 452). I think there are three ways of dealing with varicose veins. The first is that detailed in the above article by tying the " head springs" filling the superficial veins-i.e., the internal or external saphenous veins and their branches and prominent communicating veins. I find this gives good immediate results and the veins often spontaneously thrombose. In two years or so the veins reappear, especially in the leg, and later become troublesome. They have refilled from lesser communicating veins, for the varicose condition is a progressive one.

The second method is to tie the internal or external saphenous veins in one or more places and to inject a sclerosing fluid down them either with a hypodermic or a long needle. The results of this are also good, even though, as Boyd and Robertson show, some of the fluid goes into the deep veins; massive superficial thrombosis often follows. In my patients some varicosities reappeared in the leg two or four years later, but the troubie was never so acute; most patients were symptom-free.

The third attack is to tie the internal saphenous vein at the groin and ankle and to scarify its interior mechanically by a needle with a roughened head and thereby to make as certain as possible that the main stem of the internal saphenous is permanently destroyed by thrombosis and organization. In addition I slowly inject a moderate amount of sclerosing fluid to supplement this action and to permeate into the branches. This method has given the best effects in my hands. I am indebted to $\mathrm{Mr}$. Riddoch, of Birmingham, for the physical abrasion of the interior of the vein.

Symptoms of Varicose Veins.- "Are varicose veins a disabiiity?" In most cases, in my experience, emphatically yes. A few people do come because of vanity and fear of their parents' sufferings, but on the whole, since $I$ have inquired before and after operation, I am surprised at the inconvenience, pain, itching, weight, tiredness, sieeplessness, incapacitation, and expense they cause, particularly when a recurring complication develops like phlebitis, eczema, ulceration, not to mention refusal of hard work and inferiority feelings.

The Incision.-I found the vertical one gave a poor aesthetic result and that the transverse one was inadequate sometimes. I therefore combined the two into a " hockey stick" incision beginning externally in the crease of the groin and curving downwards and inwards parallel to the scrotum or labia. Its centre is where a line starting at the pubic spine intersects the groin at right angles. The exposure is perfect and the scar inconspicuous; it is almost a "normal" incision.

Deep Thrombosis.-I was aware of the passage of some of the large doses of common sait into the deep veins from the fall in blood pressure which takes place sometimes immediately afterwards and also from the occasional transient haemoglobinuria that followed its use. I still believe that it is quickly diluted into ineffectiveness. I now use a smalier bulk solution called P3G (phenol $2 \%$, glycerin $30 \%$, glucose $30 \%$, and gelatin $\left.\frac{1}{2} \%\right), 10 \mathrm{ml}$. each at the groin and ankle. A few swollen legs have occurred in my patients. They have been temporary and only cause discomfort for two to three weeks, and none have approximated to a white leg. The moment deep pain or swelling appears dicoumarol, $50 \mathrm{mg}$. t.d.s., is given and patients are kept about. The understandable impuise to lie up is restrained.

Communicating Veins.-I would thank Boyd and Robertson for their precise location by phlebograms of the large communicating veins above and below the knee. They occur often enough as primary sources to make precise diagnosis difficult unless their existence is known. It is on account of their variability in place, number, and size that I aim to permanently destroy the entire internal saphenous from the groin to the ankle. A large communicating vein does rareiy require individual ligature. With my patients most have been at the lower third of the leg, just above the ulcer area. I believe the full clearance of the varicose veins of the leg is essential for the permanent relief of dermatitis, eczema, and ulcer. This is one reason for the ligature at the internal malieolus.

Follow-up.-Finally, for the perfect aesthetic result (and this is the aim in hospital and private), I find that these patients require inspection every three, four, five, or six months, for "tidying-up" injections, for three years.

Conclusion.-The personal suffering and impairment of national efficiency due to varicose veins and their complications are enormous and generally unrealized.-I am, etc.,

London, W.1.

HAROLD Dodd.

\section{Road Accidents}

SIR,-With reference to road accidents, and particularly as regards the driver's liability, neither in your leading article (Oct. 18, p. 618), nor in Dr. Soddy's paper (p. 623), nor, incidentally, in my own letter which you were good enough to publish (May 17, p. 696) is there any mention of the individual's ability to do more than one thing at a time, or, rather, to follow more than one train of thought simultaneously. Strictly speaking, perhaps this is impossible, but from a practical point of view this mental agility is displayed in very varying degrees. One person will apparently be able to listen to and remember two or more simultaneous conversations, or even play a tolerable 